\title{
Carrying the Pain of Abuse: Gender-Specific Findings on the Relationship between Childhood Physical Abuse and Obesity in Adulthood
}

\author{
Esme Fuller-Thomson $^{a} \quad$ Deborah A. Sinclair ${ }^{a} \quad$ Sarah Brennenstuhl ${ }^{\mathrm{b}}$ \\ ${ }^{a}$ Factor-Inwentash Faculty of Social Work, ${ }^{b}$ Dalla Lana School of Public Health, University of \\ Toronto, Toronto, Canada
}

\section{Key Words}

Childhood physical abuse · Adverse childhood experiences $\cdot$ Gender $\cdot$ Health behaviors .

Socioeconomic status $\cdot$ Mental health

\begin{abstract}
Background: Childhood abuse has been associated with negative adult health outcomes, including obesity. This study sought to investigate the association between childhood physical abuse and adult obesity, while controlling for five clusters of potentially confounding factors: childhood stressors, socioeconomic indicators, marital status, health behaviors, and mental health. Methods: Representative data from the 2005 Canadian Community Health Survey were selected. The response rate was approximately $84 \%$. Gender-specific logistic regression analyses determined the association between abuse and obesity, while controlling for age and race and five clusters of potentially confounding factors. Of the 12,590 respondents with complete data, 2,787 were obese and 976 reported physical abuse as a child or adolescent by someone close to them. Results: Among women with childhood physical abuse compared to no abuse, the odds of obesity were $35 \%$ higher, even when controlling for age, race, and the five clusters of factors (odds ratio $(O R)=1.35 ; 95 \%$ confidence interval $(C I)=1.09,1.67$ ). Childhood physical abuse was not associated with adult obesity among men (OR $=1.12 ; 95 \% \mathrm{CI}=$ $0.82,1.53)$. Conclusions: This study provides one of the first population-based, gender-specific analyses of the association between childhood physical abuse and obesity controlling for a wide range of factors. The gender-specific findings require further exploration.
\end{abstract}


Fuller-Thomson et al.: Carrying the Pain of Abuse: Gender-Specific Findings on the Relationship between Childhood Physical Abuse and Obesity in Adulthood

\section{Introduction}

Obesity is among the fastest growing health risks worldwide. The USA has one of the highest rates of obesity in the world, with $36 \%$ of women and $32 \%$ of men found to be obese. Canada also faces a challenge: current estimates indicate that $25 \%$ of men and $23 \%$ of women are obese [1]. This growing phenomenon creates considerable concern among health care professionals and policy-makers given the links between obesity and life-threatening diseases including coronary artery disease, stroke, hypertension, type 2 diabetes mellitus, colon cancer, gall bladder disease, osteoarthritis, and postmenopausal cancer [2, 3]. In the USA, approximately 300,000 deaths, annually, are directly linked to obesity [4], making it the seventh leading cause of death [5]. Obesity is also connected with increased disability and decreased quality of life [6]. By 2008, obesity-related costs had soared to USD 147 billion [7].

Similarly, child maltreatment is a grave public health concern. Several key messages in a recent epidemiological study on child maltreatment in high-income countries alert us to the following trends. First, a substantial number of children are repeatedly abused creating a chronic condition of excessive stress with little opportunity for escape. Second, circumstances such as poverty, mental health concerns, and literacy issues are associated with child maltreatment. Third, child abuse has an impact on mental well-being and addictive behaviors that span across the life course [8].

Against this background, a growing body of research is suggesting an association between childhood maltreatment and adult obesity [9-17]. Childhood maltreatment can include neglect as well as physical, sexual, and emotional abuse $[9,18,19]$. While the relationship between childhood sexual abuse and obesity has received attention [17, 20,21], it has become increasingly evident that other forms of abuse may also contribute to higher body weight in adulthood. For instance, the Adverse Childhood Experiences (ACE) study reported a cumulative association between the number of adverse experiences (e.g., abuse, neglect, and other measures of family dysfunction) and a variety of life-threatening health risks in adulthood, including obesity [9].

Other non-sexual forms of abuse, such as neglect and physical abuse, have also been independently linked to an increased risk of obesity. For example, a population-based prospective study of 9- and 10-year-olds in Copenhagen found that neglected children were 7 times more likely to be obese as young adults than their non-neglected peers [13]. Similar associations have been reported elsewhere, indicating that neglected children are more likely to be obese in adolescence and/or young adulthood [12].

At least six studies have established a significant association between childhood physical abuse and obesity $[9-11,15,16,21]$. Three of these studies were based on clinical samples $[9,11,16]$. Two were population-based surveys: a US prospective cohort study, which followed a national sample of adolescents into adulthood [10], and a British prospective study, which followed the 1958 birth cohort with biomedical interviews at 45 years of age [15]. Finally, one study was a prospective assessment of the link between documented cases of childhood abuse and adult obesity [22]. More specifically, a sample of 410 court-substantiated cases of abused or neglected children was matched with a group of non-abused children ( $17 \%$ of the sample was physically abused). Results collected over four decades indicated that childhood physical abuse predicted significantly higher BMI scores in adulthood, controlling for socioeconomic demographics, smoking, and alcohol use.

While there is growing evidence of a relationship between childhood maltreatment and obesity, only a portion of studies has focused on physical abuse, and only a few of these have used population-based samples. Moreover, research has not consistently controlled for a range of confounding factors, including family background, health behaviors, socioeconomic status, and mental health. Each of these will be discussed in more detail below. 
Fuller-Thomson et al.: Carrying the Pain of Abuse: Gender-Specific Findings on the

Relationship between Childhood Physical Abuse and Obesity in Adulthood

\section{Potential Confounding Factors}

\section{Family Background}

Childhood maltreatment takes place within a complex set of adverse circumstances. For instance, child maltreatment has been associated with parental addictions [9, 23, 24], parental divorce, blended families and single-led families [24-28], and parental poverty and unemployment $[25,28,29]$. Childhood stressors, such as poverty [30], single parent-led families, and parental alcohol problems, are also related to the development of adult obesity [31].

\section{Health Behaviors}

Adults abused during childhood have elevated risks of alcohol misuse, smoking $[9,27,32$, 33], and physical inactivity [9]. Obesity is also positively associated with alcohol use [34, 35] and physical inactivity $[34,36]$. Moreover, while adult smokers are less likely to be obese than non-smokers, smokers typically gain weight when they quit smoking [34]. Indeed, nearly half of American overweight and obese men and a quarter of similar women over the age 50 are former smokers [37].

\section{Socioeconomic Status}

Children who are abused experience greater difficulties in school resulting in poorer outcomes, potentially compromising career opportunities in later life [27, 38, 39]. Childhood physical abuse has been associated with a decline in socioeconomic status by adulthood, which may be compounded by other stressors, such as divorce [27]. Obesity is also correlated with socioeconomic indicators, including poverty and low education $[1,40]$; however, gender differences have been reported. For example, in the USA, low education is associated with higher obesity rates among women, but not among men [1]. The association between poverty and obesity may be, in part, related to the inexpensive cost of energy-dense foods compounded by the comforting nature of sugar and fat [30].

\section{Mental Health}

Childhood physical abuse is a risk factor for depression and anxiety later in life [9, 24, 41]. Mental health problems and obesity are also correlated [42]; although, gender differences are apparent. For example, while depression is positively associated with obesity among women, the relationship is less clear among men $[42,43]$. Higher odds of anxiety disorders have been reported among both men and women with obesity [35].

Other important variables to control when assessing the abuse-obesity relationship include age, race, and gender, which are each significantly correlated with obesity [1].

\section{Current Study}

The goal of this study was to extend previous research exploring the relationship between physical childhood abuse and adult obesity through the use of a representative, populationbased sample and gender-specific analyses, while controlling for a large range of potentially confounding factors. These include the following: childhood stressors, adult health behaviors, adult socioeconomic status, and mental health history. 


\section{Participants and Methods}

\section{Data Source and Sample}

Data were derived from the 2005 Canadian Community Health Survey (CCHS) [44], which provides estimates of health determinants, health status, and health system utilization at sub-provincial, provincial, and national levels. The CCHS used a multi-staged stratified cluster design in which the dwelling or 'household' was the final sampling unit. In households selected for the study, a person designated as knowledgeable about the household was asked to provide basic demographic information for all its residents. In every household, one person was then selected for an in-depth interview using varying probabilities that took age and the household composition into account. The 2005 CCHS was representative of approximately $98 \%$ of Canadians aged 12 years and older [44].

The present study was restricted to CCHS respondents from the provinces of Manitoba and Saskatchewan, which were the only regions that selected an optional content module on childhood stressors that included a question on childhood physical abuse. The provincial-level response rates were $83.3 \%$ and $84.1 \%$ for Manitoba and Saskatchewan, respectively [44].

In total, there were 13,640 respondents aged 18 years and older in Manitoba and Saskatchewan; however, 581 respondents did not provide adequate information to calculate their BMI, and an additional 469 respondents were missing data on childhood physical abuse. Thus, the final sample size for the crosstab examining childhood physical abuse and obesity was 12,590 ( $\operatorname{men}=5,703$; women $=6,887$ ), which was $92.3 \%$ of the original sample. Of these respondents, 2,787 were obese and 976 reported that they had been physically abused during their childhood or adolescence.

To better understand the potential bias introduced by missing data, chi-square tests were conducted. These tests indicated that those with and without complete data on BMI had comparable rates of childhood physical abuse ( $p=0.48$ for women; $p=0.80$ for men). For women, responders and non-responders to the abuse question also had comparable rates of obesity $(\mathrm{p}=0.10)$; however, men with missing data on abuse were significantly more likely to be obese than men without ( 28.2 vs. $21.1 \%$; $=0.003$ ). A total of $5.1 \%$ of males did not respond to the abuse question.

\section{Measures}

Individuals were determined to have experienced childhood physical abuse based on a question found in a section of the survey about childhood experiences. The section was preceded by the following instructions: 'The next few questions ask about some things that may have happened to you while you were a child or a teenager, before you moved out of the house. Please tell me if any of these things have happened to you'. Individuals who responded 'yes' to the question: 'Were you ever physically abused by someone close to you?' were ascertained as having been abused. Questions about other forms of childhood maltreatment, such as sexual abuse or emotional abuse and neglect, were not available anywhere in the data set.

Obesity was determined based on self-reported weight and height. Those with a BMI $\geq 30 \mathrm{~kg} / \mathrm{m}^{2}$ were classified as obese.

Demographic control variables included age (18-29 years, then by decade to 80 years and older) and self-reported race (white and visible minority). Analyses were stratified by gender.

Questions on childhood stressors were included in the same part of the survey as childhood abuse and included the following: i) parental divorce as determined by the question: 'Did your parents get a divorce?'; ii) parental addiction using the question: 'Did either of your parents drink or use drugs so often that it caused problems for the family?'; and, iii) parental unemployment based on the question: 'Did your father or mother not have a job for a long time when they wanted to be working?'.

Measures of current socioeconomic status included educational attainment and household income. Educational attainment was assessed by highest level of education, which included the following response categories: less than high school graduation, high school graduation, and post-secondary graduation. Household income was assessed according to the following income categories: USD 0-14,999, USD 15,00029,999, USD 30,000-49,999, or USD 50,000 or more. A missing category was also included.

Marital Status was dichotomized into never married, separated or divorced versus married or living common-law.

The health behaviors assessed included physical activity level, smoking status, and alcohol use. Physical activity level was based on a derived variable provided by Statistics Canada created from responses to a 
Fuller-Thomson et al.: Carrying the Pain of Abuse: Gender-Specific Findings on the Relationship between Childhood Physical Abuse and Obesity in Adulthood

series of questions about the respondent's daily recreational physical activity lasting more than 15 min. Response categories included active, moderate, and inactive. Smoking status was also based on a derived variable created from a series of questions pertaining to the respondent's smoking habits and was collapsed into the following categories: current smoker and former smoker versus non-smoker. Alcohol use was assessed by daily average consumption according to the categories: abstainer/very light drinker (nondrinker or average of zero drinks per day), low consumption (women: one drink per day; men: one or two drinks per day), and hazardous/harmful consumption (women: two or more drinks per day; men: three or more drinks per day).

Mental health comprised a history of mood and anxiety disorders. Respondents were asked whether they had ever been diagnosed by a health professional with 'a mood disorder such as depression, bipolar disorder, mania, or dysthymia' or if they had an 'anxiety disorder such as a phobia, obsessive compulsive disorder, or a panic disorder'.

\section{Statistical Analyses}

The purpose of the analyses was to determine: (i) if there was an elevated odds ratio (OR) of obesity for individuals reporting that they had been physically abused as a child in comparison to the non-abused, while adjusting for gender, age, and race; and (ii) the extent to which inclusion of each of the clusters of risk factors independently and then cumulatively changed the association between abuse and obesity. Gender-specific analysis was undertaken to account for differences in obesity [1]. For each gender, seven consecutive logistic regression analyses were conducted with obesity as the outcome. Childhood physical abuse, age, and race were included in the first and each subsequent model. In the second model, childhood stressors including parental divorce, parental addictions, and parental unemployment were included. The third model included socioeconomic status (education and household income). The fourth model controlled for marital status. The fifth model adjusted for health behaviors, such as physical activity level, smoking, and alcohol use. The sixth model included the history of mood and anxiety disorders. The seventh and final model adjusted for all the factors identified above. Due to missing data on one or more variables in the logistic regression models, sample sizes varied modestly: In the first model, the sample size was 6,835 for females and 5,622 for males. In the fully adjusted model, the sample sizes decreased to 6,635 and 5,361, respectively.

\section{Results}

Approximately one in five adults from Manitoba and Saskatchewan were found to be obese, measured by a BMI larger than $30 \mathrm{~kg} / \mathrm{m}^{2}$ (men $=21.1 \%$; women $\left.=18.2 \%\right)$. A smaller proportion of the sample reported physical abuse during childhood or adolescence by someone close to them (men $=4.9 \%$; women $9.7 \%$ ).

Table 1 provides the results of the final gender-specific logistic regression models that control for all six clusters of potentially confounding variables simultaneously. It was found that women who were physically abused as children or adolescents had $35 \%$ higher odds of obesity than their non-abused peers; however, physically abused men were no more likely to be obese than their non-abused counterparts.

Figures 1 and 2 show the results of the full series of analyses controlling for each cluster of potentially confounding factors alone and then altogether. As shown in figure 1, the OR of obesity among women adjusted for age and race was 1.47. Neither adjustment for each cluster of factors alone nor adjustment for clusters of factors altogether resulted in a substantial reduction in the abuse-obesity association. There was a modest decrease in the association between childhood physical abuse and adult obesity when mood and anxiety disorders were controlled for $(\mathrm{OR}=1.40)$ and when SES was included in the analysis (OR = 1.36). Nonetheless, the abuse-obesity association remained statistically significant across all seven models investigated. For men, as is shown in figure 2, the abuse-obesity association did not reach statistical significance in any of the seven models. 
Fuller-Thomson et al.: Carrying the Pain of Abuse: Gender-Specific Findings on the Relationship between Childhood Physical Abuse and Obesity in Adulthood

Table 1. Logistic regression analyses of obesity in a regional sample of women and men from Manitoba and Saskatchewan ${ }^{\mathrm{a}}$

\begin{tabular}{|c|c|c|c|c|}
\hline & \multicolumn{2}{|l|}{ Men } & \multicolumn{2}{|c|}{ Women } \\
\hline & OR & $95 \% \mathrm{CI}$ & OR & $95 \% \mathrm{CI}$ \\
\hline \multicolumn{5}{|l|}{ Exposure variable } \\
\hline \multicolumn{5}{|l|}{ Physically abused as a child } \\
\hline No & 1.00 & referent & 1.00 & \multirow{2}{*}{$\begin{array}{l}\text { referent } \\
(1.09,1.67)^{* *}\end{array}$} \\
\hline Yes & 1.12 & $(0.82,1.53)$ & 1.35 & \\
\hline \multicolumn{5}{|l|}{ Demographic variables } \\
\hline \multicolumn{5}{|l|}{ Age, years } \\
\hline $18-29$ & 1.00 & referent & 1.00 & \multirow{7}{*}{$\begin{array}{l}\text { referent } \\
(1.00,1.62)^{*} \\
(1.26,1.97)^{* * *} \\
(1.56,2.46)^{* * *} \\
(1.17,1.97)^{* *} \\
(1.11,1.93)^{* *} \\
(0.57,1.17)\end{array}$} \\
\hline $30-39$ & 1.52 & $(1.19,1.93)^{* *}$ & 1.28 & \\
\hline $40-49$ & 1.69 & $(1.33,2.14)^{* * *}$ & 1.57 & \\
\hline $50-59$ & 1.94 & $(1.52,2.47)^{* * *}$ & 1.96 & \\
\hline $60-69$ & 1.84 & $(1.40,2.43)^{* * *}$ & 1.51 & \\
\hline $70-79$ & 1.06 & $(0.76,1.49)$ & 1.46 & \\
\hline $80+$ & 0.44 & $(0.25,0.80)^{* *}$ & 0.81 & \\
\hline \multicolumn{5}{|l|}{ Race } \\
\hline White & 1.00 & referent & 1.00 & \multirow{2}{*}{$\begin{array}{l}\text { referent } \\
(1.00,1.45)\end{array}$} \\
\hline Visible minority & 0.63 & $(0.50,0.79)^{* * *}$ & 1.20 & \\
\hline \multicolumn{5}{|l|}{ Childhood stressors } \\
\hline \multicolumn{5}{|l|}{ Parental divorce } \\
\hline No & 1.00 & referent & 1.00 & \multirow{2}{*}{$\begin{array}{l}\text { referent } \\
(0.80,1.23)\end{array}$} \\
\hline Yes & 0.91 & $(0.73,1.14)$ & 0.99 & \\
\hline \multicolumn{5}{|l|}{ Parental addiction } \\
\hline No & 1.00 & referent & 1.00 & \multirow{2}{*}{$\begin{array}{l}\text { referent } \\
(0.82,1.19)\end{array}$} \\
\hline Yes & 1.21 & $(0.98,1.48)$ & 0.99 & \\
\hline \multicolumn{5}{|l|}{ Parental unemployment } \\
\hline No & 1.00 & referent & 1.00 & \multirow{2}{*}{$\begin{array}{l}\text { referent } \\
(0.83,1.28)\end{array}$} \\
\hline Yes & 1.48 & $(1.16,1.87)^{* *}$ & 1.03 & \\
\hline \multicolumn{5}{|l|}{ Adult socioeconomic status } \\
\hline \multicolumn{5}{|l|}{ Education } \\
\hline Less than high school & 1.26 & $(1.05,1.51)^{*}$ & 1.24 & \multirow{3}{*}{$\begin{array}{l}(1.03,1.50)^{*} \\
(0.83,1.13) \\
\text { referent }\end{array}$} \\
\hline High school graduate & 0.98 & $(0.83,1.16)$ & 0.97 & \\
\hline Post-secondary graduate & 1.00 & referent & 1.00 & \\
\hline \multicolumn{5}{|l|}{ Household income } \\
\hline Missing data & 0.86 & $(0.67,1.09)$ & 0.88 & $(0.70,1.10)$ \\
\hline No or $<$ USD 15,000 & 1.45 & $(1.03,2.04)^{*}$ & 1.62 & $(1.24,2.10)^{* * *}$ \\
\hline USD 15,000-29,999 & 0.85 & $(0.65,1.11)$ & 1.35 & $(1.09,1.66)^{* *}$ \\
\hline USD 30,000-49,999 & 0.89 & $(0.74,1.07)$ & 1.39 & $(1.16,1.65)^{* * *}$ \\
\hline USD 50,000 or more & 1.00 & referent & 1.00 & referent \\
\hline \multicolumn{5}{|l|}{ Marital status } \\
\hline Not married & 1.00 & referent & 1.00 & \multirow{2}{*}{$\begin{array}{l}\text { referent } \\
(0.88,1.18)\end{array}$} \\
\hline Married & 1.57 & $(1.32,1.87)^{* * *}$ & 1.02 & \\
\hline
\end{tabular}

Table 1 continued on next page 
Fuller-Thomson et al.: Carrying the Pain of Abuse: Gender-Specific Findings on the

Table 1. Continued

\begin{tabular}{|c|c|c|c|c|}
\hline & \multicolumn{2}{|l|}{ Men } & \multicolumn{2}{|c|}{ Women } \\
\hline & OR & $95 \% \mathrm{CI}$ & OR & $95 \% \mathrm{CI}$ \\
\hline \multicolumn{5}{|l|}{ Current health behaviours } \\
\hline \multicolumn{5}{|l|}{ Physical activity level } \\
\hline Active & 1.00 & referent & 1.00 & referent \\
\hline Moderate & 1.37 & $(1.11,1.69)^{* *}$ & 1.59 & $(1.28,1.98)^{* * *}$ \\
\hline Inactive & 1.80 & $(1.50,2.15)^{* * *}$ & 2.21 & $(1.82,2.68)^{* * *}$ \\
\hline \multicolumn{5}{|l|}{ Smoking status } \\
\hline Current or former smoker & 1.30 & $(1.10,1.53)^{* *}$ & 1.10 & $(0.95,1.26)$ \\
\hline Never smoker & 1.00 & referent & 1.00 & referent \\
\hline \multicolumn{5}{|l|}{ Alcohol use } \\
\hline Abstainer/Very light drinker & 1.05 & $(0.76,1.44)$ & 1.84 & $(1.23,2.75)^{* *}$ \\
\hline Lower consumption & 1.09 & $(0.78,1.52)$ & 1.23 & $(0.80,1.89)$ \\
\hline Higher consumption & 1.00 & referent & 1.00 & referent \\
\hline \multicolumn{5}{|l|}{ Mental health } \\
\hline \multicolumn{5}{|l|}{ History of mood disorder } \\
\hline No & 1.00 & referent & 1.00 & referent \\
\hline Yes & 1.13 & $(0.78,1.64)$ & 1.66 & $(1.31,2.09)^{* * *}$ \\
\hline \multicolumn{5}{|l|}{ History of anxiety disorder } \\
\hline No & 1.00 & referent & 1.00 & referent \\
\hline Yes & 0.78 & $(0.50,1.22)$ & 0.79 & $(0.59,1.06)$ \\
\hline
\end{tabular}

a Sample sizes are presented in their unweighted form. Odds ratios and 95\% confidence intervals are weighted to adjust for the probability of selection and non-response according to Statistics Canada data release guidelines.

$\mathrm{OR}=$ Odds ratio; $\mathrm{CI}=$ confidence interval. ${ }^{*} \mathrm{p}<0.05 .{ }^{* *} \mathrm{p}<0.01 .{ }^{* * *} \mathrm{p}<0.001$.

Data source: Canadian Community Health Survey, 2005.

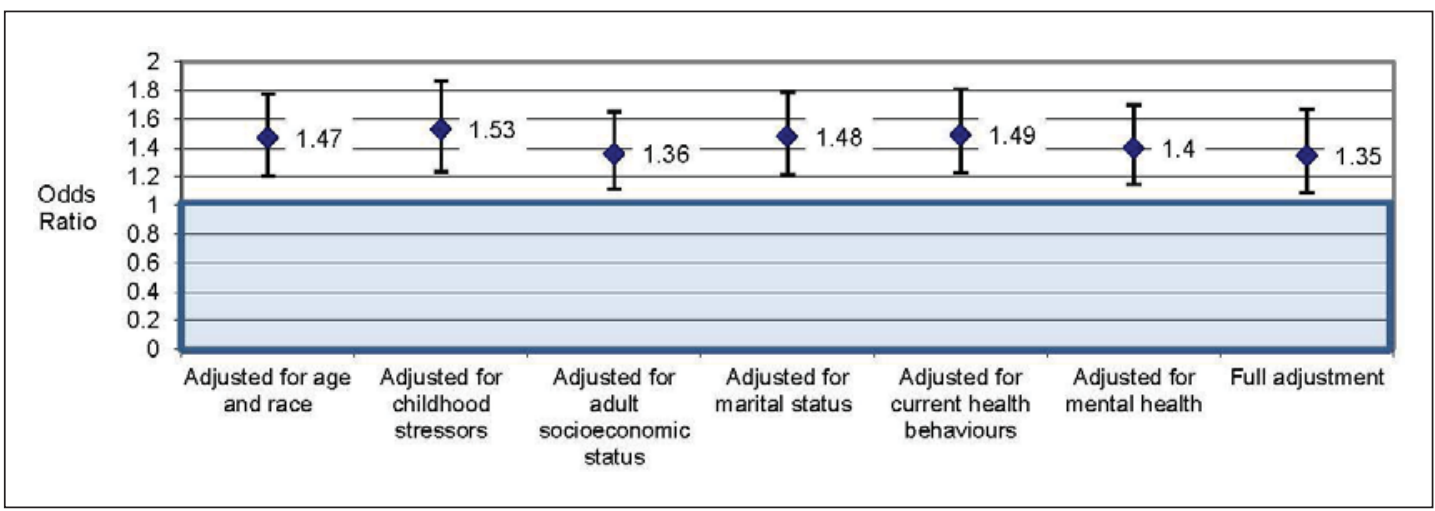

Fig. 1. Odds ratio and 95\% confidence interval of obesity among women reporting childhood physical abuse versus women not reporting abuse. All data are adjusted for age and race. Sample sizes range from $\mathrm{n}=6,835$ in the first model to $n=6,635$ in the fully adjusted model. Source: Representative, regional sample of the Canadian Community Health Survey, 2005. 
Fuller-Thomson et al.: Carrying the Pain of Abuse: Gender-Specific Findings on the

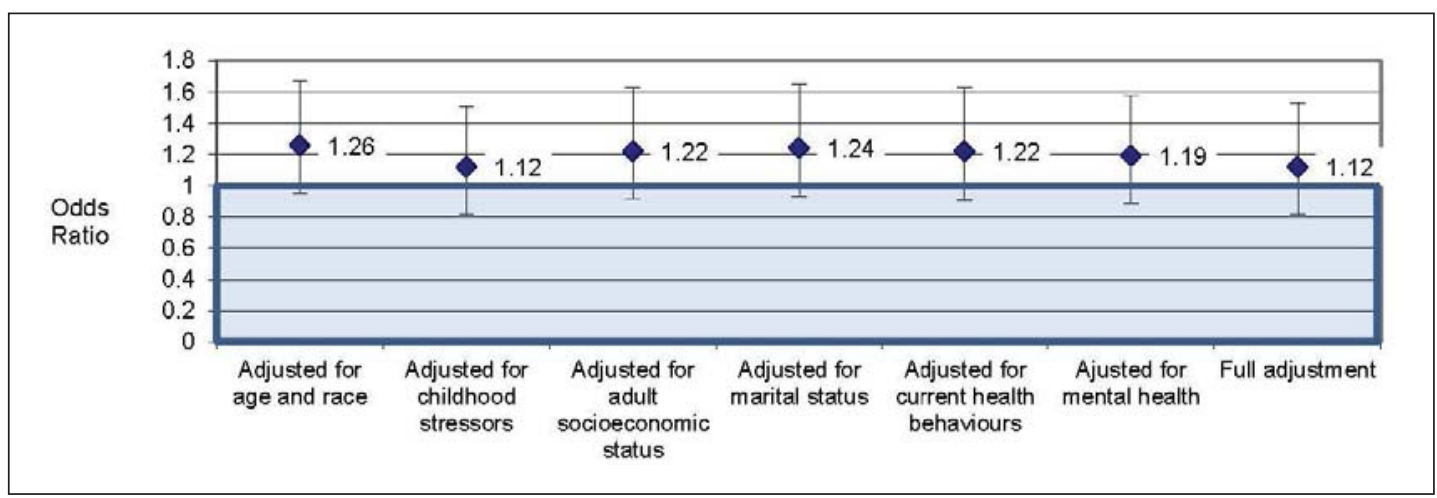

Fig. 2. Odds ratio and 95\% confidence interval of obesity among men reporting childhood physical abuse versus men not reporting abuse. All data are adjusted for age and race. Sample sizes range from $n=5,622$ in the first model to $n=5,361$ in the fully adjusted model. Source: Representative, regional sample of the Canadian Community Health Survey, 2005.

\section{Discussion}

Women physically abused in childhood had higher odds of obesity in adulthood than women who had not been physically abused. For men, childhood physical abuse was not associated with obesity. To our knowledge, this is one of the only studies conducting genderspecific analyses of the physical abuse-obesity relationship using a representative sample and controlling for a wide range of potential confounders. These findings underline the importance of conducting gender-specific analyses when examining the influence of early adverse experiences on adult health outcomes.

It is unclear why childhood physical abuse is associated with adult obesity among women but not men; however, this finding is consistent with previous research on sexual abuse and obesity [21]. It has been suggested that the abuse-obesity association found among women may relate to gender differences in the relationship between trauma and body image [21] and the coping mechanisms chosen to deal with the stress associated with abuse [45]. As for the former, it has been theorized that sexually abused girls overeat in order to make themselves less sexually attractive to males $[45,46]$. It is also possible that body size is used adaptively by physically abused females who learn that their body weight can be used to shield themselves from the abuse. Alternatively, it may reflect gender differences in coping mechanisms. The comforting nature of sugar and fat [30] has been well established, and females may be more likely to seek out 'comfort food' to self-soothe under stress than are males [47].

We had anticipated that the association between childhood physical abuse and obesity would be attenuated by other factors, including childhood stressors, health behaviors, mental health, and socioeconomic position. However, our analyses did not support this hypothesis. Some of these factors had no impact, while others only had a minimal effect on the strength of the abuse-obesity association among women. It is possible that other factors not controlled for in our analyses may be important for explaining the relationship. Indeed, it has been hypothesized that adverse childhood experiences, such as childhood abuse, 'get under the skin' through disruptions to the normal development of biological systems, particularly the hypothalamic-pituitary-adrenal (HPA) axis, that affect stress regulation and, in turn, health throughout the life course [48-50]. A number of scholars have explored the HPA axis mechanism in response to chronic stress, such as childhood physical abuse, and how this leads to an overproduction of cortisol and insulin and, in turn, the impairment of the appetite regu- 
Fuller-Thomson et al.: Carrying the Pain of Abuse: Gender-Specific Findings on the Relationship between Childhood Physical Abuse and Obesity in Adulthood

lation mechanism and the typical pattern of fat distribution [51, 52]. Future research should use direct biological measures, such as cortisol, to explore potential sex/gender-based differences in how the dysfunctional stress response affects body weight.

There are several important limitations to the current research that must be considered when interpreting the results. One of the major drawbacks of this study was the way that childhood physical abuse was measured in the CCHS. It is well accepted that the use of a single question is less valid than a series of questions or a scale. McMillan et al. [53] used seven questions to assess childhood physical abuse in their analysis of the Ontario Health Supplement. Using this method, they found a higher overall prevalence of physical abuse than reported in this study (i.e., women 21 vs. $9.7 \%$ and men 31 vs. $4.9 \%$ ). However, our estimates were more similar to the prevalence reported for severe physical abuse (i.e., women $9 \%$ and men $11 \%$ ) suggesting that the single-question approach used by the CCHS may bias respondents toward the report of only the most severe experience of abuse. Unfortunately, national Canadian population-based data on childhood abuse are not available for comparison [54]. The retrospective nature of the abuse question is also problematic due to the increased potential for recall bias. That being said, two prospective studies evaluating the impact of recall bias concluded that children with substantiated physical abuse were more likely to underreport their history of childhood abuse as adults $[55,56]$. Consequently, if this type of underreporting was also found in the CCHS sample, then our results would be biased towards the null hypothesis.

Relating to the problems associated with the abuse question is the finding that men with missing data on abuse were significantly more likely to be obese than men who responded to the abuse question. If we hypothesize that non-responders to the abuse question are disproportionately more likely to have experienced abuse, it would appear that our findings may underestimate the association between childhood physical abuse and obesity in men. Future gender-specific research using population-based data will be needed to validate our findings.

Another important shortcoming of this study was the use of self-reported weight and height data to calculate BMI. It is generally found that women underreport their body weight and both women and men overreport their height [57]. Therefore, it is possible that obesity estimates are lower than what they would be if direct measures of weight and height were used. That being said, under-estimation of obesity would have rendered our results more conservative.

The measurement of some risk factors may also be a shortcoming of this study due to the use of single-item indicators (e.g., childhood stressors and mental health). Future studies could improve on the current research through the use of more detailed assessments of variables such as mood and anxiety disorders, which are likely to be underreported using singleitem questions based on a health professional diagnosis. Lastly, while childhood physical abuse is a complex topic, the CCHS did not address contextual elements of abuse, such as the frequency or the severity of childhood physical abuse and the identity of the perpetrator, nor did it investigate other forms of child maltreatment. Each of these factors may be important to deepen our understanding of the childhood physical abuse-obesity relationship.

Despite these limitations, this study has many strengths that make it a unique contribution to the literature. These include the use of a large representative, population-based survey with a good response rate and a wide selection of variables that could be used for modeling (i.e., childhood stressors, health behaviors, socioeconomic status, mental health).

In conclusion, our findings suggest that women who were physically abused as children or adolescents have higher odds of adult obesity in comparison to their non-abused peers. While obesity prevention has tended to focus on diet and exercise, the results of this study suggest the importance of more distal factors for preventing obesity. In particular, this study contributes to the growing literature demonstrating the importance of providing children 
Fuller-Thomson et al.: Carrying the Pain of Abuse: Gender-Specific Findings on the

with nurturing environments [58]. In light of the magnitude of the obesity epidemic and the large number of adults who report that they have been physically abused in childhood, this topic merits further investigation.

\section{Acknowledgement}

This research was undertaken, in part, thanks to support for the first author from the Sandra Rotman Endowed Chair in Social Work.

\section{Disclosure Statement}

The authors have no conflicts of interest to report.

\section{References}

1 Sassi F: Obesity and the Economics of Prevention: Fit not Fat. Organization for Economic Cooperation and Development, 2010.

2 Katzmarzyk PT, Janssen I: The economic costs associated with physical inactivity and obesity in Canada: an update. Can J Appl Physiol 2004;29:90-115.

3 Clinical Guidelines on the Identification, Evaluation, and Treatment of Overweight and Obesity in Adults. 1998. www.nhlbi.nih.gov/guidelines/obesity/ob_gdlns.pdf.

4 Flegal KM, Graubard BI, Williamson DF, Gail MH: Excess deaths associated with underweight, overweight, and obesity. JAMA 2005;293:1861-1867.

5 Wellman NS, Friedberg B: Causes and consequences of adult obesity: health, social and economic impacts in the United States. Asia Pac J Clin Nutr 2002;11:705-709.

6 Luo Y, Waite LJ: The impact of childhood and adult SES on physical, mental, and cognitive well-being in later life. J Gerontol B Psychol Sci Soc Sci 2005;60:S93-S101.

7 Finkelstein EA, Trogdon JG, Cohen JW, Dietz W: Annual medical spending attributable to obesity: payer-and service-specific estimates. Health Aff 2009;28:w822-831.

-8 GilbertR, Widom CS, Browne K, Fergusson D, Webb E, Janson S: Burden and consequences of child maltreatment in high-income countries. Lancet 2009;373:68-81.

-9 Felitti VJ, Anda RF, Nordenberg D, Williamson DF, Spitz AM, Edwards V, Koss MP, Marks JS: Relationship of childhood abuse and household dysfunction to many of the leading causes of death in adults. The Adverse Childhood Experiences (ACE) Study. Am J Prev Med 1998;14:245-258.

$\rightarrow 10$ Hussey JM, Chang JJ, Kotch JB: Child maltreatment in the United States: prevalence, risk factors, and adolescent health consequences. Pediatrics 2006;118:933-942.

-11 Jia H, Li JZ, Leserman J, Hu Y, Drossman DA: Relationship of abuse history and other risk factors with obesity among female gastrointestinal patients. Dig Dis Sci 2004;49:872-877.

12 Johnson JG, Cohen P, Kasen S, Brook JS: Childhood adversities associated with risk for eating disorders or weight problems during adolescence or early adulthood. Am J Psychiatry 2002;159:394-400.

13 Lissau I, Sorensen TI: Parental neglect during childhood and increased risk of obesity in young adulthood. Lancet 1994;343:324-327.

14 Noll JG, Zeller MH, Trickett PK, Putnam FW: Obesity risk for female victims of childhood sexual abuse: a prospective study. Pediatrics 2007;120:e61-67.

15 Thomas C, Hypponen E, Power C: Obesity and type 2 diabetes risk in midadult life: the role of childhood adversity. Pediatrics 2008;121:e1240-1249.

16 Williamson DF, Thompson TJ, Anda RF, Dietz WH, Felitti V: Body weight and obesity in adults and self-reported abuse in childhood. Int J Obes Relat Metab Disord 2002;26:1075-1082.

17 Gustafson TB, Sarwer DB: Childhood sexual abuse and obesity. Obes Rev 2004;5:129-135.

18 English DJ: The extent and consequences of child maltreatment. Future Child 1998;8:39-53.

19 Wildes JE, Kalarchian MA, Marcus MD, Levine MD, Courcoulas AP: Childhood maltreatment and psychiatric morbidity in bariatric surgery candidates. Obes Surg 2008;18:306-313.

20 Felitti VJ: Long-term medical consequences of incest, rape, and molestation. South Med J 1991;84:328-331.

21 Mamun AA, Lawlor DA, O'Callaghan MJ, Bor W, Williams GM, Najman JM: Does childhood sexual abuse predict young adult's BMI? A birth cohort study. Obesity 2007;15:2103-2110.

22 Bentley T, Widom CS: A 30-year follow-up of the effects of child abuse and neglect on obesity in adulthood. Obesity 2009;17:1900-1905. 
Fuller-Thomson et al.: Carrying the Pain of Abuse: Gender-Specific Findings on the Relationship between Childhood Physical Abuse and Obesity in Adulthood

23 Dube SR, Felitti VJ, Dong M, Giles WH, Anda RF: The impact of adverse childhood experiences on health problems: evidence from four birth cohorts dating back to 1900. Prev Med 2003;37:268-277.

24 Springer KW, Sheridan J, Kuo D, Carnes M: Long-term physical and mental health consequences of childhood physical abuse: results from a large population-based sample of men and women. Child Abuse Negl 2007;31: 517-530.

25 Brown T, Frederico M, Hewitt L, Sheehan R: Revealing the existence of child abuse in the context of marital breakdown and custody and access disputes. Child Abuse Negl 2000;24:849-859.

26 Colman RA, Widom CS: Childhood abuse and neglect and adult intimate relationships: a prospective study. Child Abuse Negl 2004;28:1133-1151.

27 Mullen P, Martin J, Anderson J, Romans S, Herbison G: The long-term impact of the physical, emotional, and sexual abuse of children: a community study. Child Abuse Negl 1996;20:7-21.

28 Turner HA, Finkelhor D, Ormrod R: Family structure variations in patterns and predictors of child victimization. Am J Orthopsychiatry 2007;77:282-295.

29 Zielinski DS: Child maltreatment and adult socioeconomic well-being. Child Abuse Negl 2009;33:666-678.

-30 Drewnowski A, Specter S: Poverty and obesity: the role of energy density and energy costs. Am J Clin Nutr 2004;79:6-16.

-31 Kestilä L, Rahkonen 0, Martelin T, Lahti-Koski M, Koskinen S: Do childhood social circumstances affect overweight and obesity in early adulthood? Scand J Public Health 2009;37:206-219.

32 Anda RF: The enduring effects of abuse and related adverse experiences in childhood. Eur Arch Psychiatry Clin Neurosci 2006;256:174-186.

33 Melchior M, Moffitt TE, Milne BJ, Poulton R, Caspi A: Why do children from socioeconomically disadvantaged families suffer from poor health when they reach adulthood? A life-course study. Am J Epidemiol 2007;166: 966-974.

34 Kruger J, Ham SA, Prohaska TR: Behavioral risk factors associated with overweight and obesity among older adults: the 2005 National Health Interview Survey. Prev Chron Dis 2009;6:A14.

-35 Petry NM, Barry D, Pietrzak RH, Wagner JA: Overweight and obesity are associated with psychiatric disorders: results from the national epidemiologic survey on alcohol and related conditions. Psychosom Med 2008;70: 288-297.

36 Thyfault JP, Booth FW: Lack of regular physical exercise or too much inactivity. Curr Opin Clin Nutr Metab Care 2011;14:374-378.

37 Centers for Disease Control and Prevention (CDC): Cigarette smoking among adults and trends in smoking cessation - United States, 2008. MMWR Morb Mortal Wkly Rep 2009;58:1227-1232.

-38 Perez CM, Widom CS: Childhood victimization and long-term intellectual and academic outcomes. Child Abuse Negl 1994;18:617-633.

39 Whiting CC: School performance of children who have experienced maltreatment. Phys Occup Ther Pediatr 2001;21:81-89.

40 Bryan S, Walsh P: Physical activity and obesity in Canadian women. BMC Women's Health 2004;4(suppl 1):S6.

-41 McCauley J, Kern DE, Kolodner K, Dill L, Schroeder AF, DeChant HK, Ryden J, Derogatis LR, Bass EB: Clinical characteristics of women with a history of childhood abuse: unhealed wounds. JAMA 1997;277:1362-1368.

-42 Carpenter K, Hasin D, Allison D, Faith M: Relationships between obesity and DSM-IV major depressive disorder, suicide ideation, and suicide attempts: results from a general population study. Am J Public Health 2000;90: 251-257.

43 Atlantis E, Baker M: Obesity effects on depression: systematic review of epidemiological studies. Int J Obes 2008;32:881-891.

44 Canadian Community Health Survey (CCHS). Cycle 3.1 (2005). Public Use Microdata File (PUMF) User Guide, 2006. http://data.library.utoronto.ca/datapub/codebooks/cstdli/cchs/cycle3_1/Documentation/GUIDE_E.pdf.

45 Felitti VJ: Childhood sexual abuse, depression, and family dysfunction in adult obese patients: a case control study. South Med J 1993;86:732-736.

46 Wiederman MW, Sansone RA, Sansone LA: Obesity among sexually abused women: an adaptive function for some? Women Health 1999;29:89-100.

47 Dube L, LeBel JL, Lu J: Affect asymmetry and comfort food consumption. Physiol Behav 2005;86:559-567.

48 Hertzman C, Wiens M: Child development and long-term outcomes: a population health perspective and summary of successful interventions. Soc Sci Med1996;43:1083-1095.

49 Hertzman C: The biological embedding of early experience and its effects on health in adulthood. Ann N Y Acad Sci 1999;896:85-95.

50 Power C, Hertzman C: Social and biological pathways linking early life and adult disease. Br Med Bull 1997; 53:210-221.

51 Coccurello R, D’Amato FR, Moles A: Chronic social stress, hedonism and vulnerability to obesity: lessons from rodents. Neurosci Biobehav Rev 2009;33:537-550.

52 Greenfield EA, Marks NF: Profiles of physical and psychological violence in childhood as a risk factor for poorer adult health: evidence from the 1995-2005 National Survey of Midlife in the United States. J Aging Health 2009;21:943-966.

53 MacMillan HL, Fleming JE, Trocme N, Boyle MN, Wong M, Racine YA, Beardslee WR, Offord DR: Prevalence of child physical and sexual abuse in the community - results from the Ontario Health Supplement. JAMA 1997; 278:131-135. 
Fuller-Thomson et al.: Carrying the Pain of Abuse: Gender-Specific Findings on the Relationship between Childhood Physical Abuse and Obesity in Adulthood

54 Afifi TO: Child maltreatment in Canada: an understudied public health problem. Can J Pub Health 2011;102: 459-461.

55 Femina DD, Yeager CA, Lewis DO: Child abuse: adolescent records vs. adult recall. Child Abuse Negl 1990;14: 227-231.

56 Williams LM: Recovered memories of abuse in women with documented child sexual victimization histories. J Traum Stress 1995;8:649-673.

57 Sheilds MG: Estimates of obesity based on self-reports versus direct measures. Health Rep 2008;19:1-16.

58 Irwin LG, Siddiqi A, Hertzman C: Early Child Development: A Powerful Equalizer. Final Report for the World Health Organization's Commission on Social Determinants of Health. 2007. 